\title{
OS IMPACTOS DA VULNERABILIDADE SOCIAL NA CONSTRUÇÃO DA SUBJETIVIDADE
}

DOI: 10.22289/2446-922X.V7N2A4

Mateus Ferreira de Almeida

Mike Alexander de Paula Pinto

Luiz Felipe Viana Cardoso ${ }^{1}$

\section{RESUMO}

Esta pesquisa teve como objetivo realizar um estudo sobre o conceito de vulnerabilidade social e seus impactos na construção da subjetividade, utilizando-se para isso revisões bibliográficas que pudessem abarcar os anos de 1990 e 2020. A discussão teve como subsídio a Psicologia Social Crítica, com ela foi possível visualizar o contexto de vulnerabilidade social como marcador de subjetividades. Desta forma, tratamos os conceitos de vulnerabilidade e subjetividade a partir de suas diversidades de compreensões, onde trabalhamos tanto em suas etimologias, considerando suas múltiplas possibilidades de leituras, quanto em suas aplicações sob a perspectiva da Psicologia Social Crítica. Portanto, concluímos que a relação da vulnerabilidade social na construção das subjetividades humanas, se dão de forma correlatas, pois foi possível observar as multi-interações com as quais os fenômenos "vulnerabilidade" e "subjetividade" se constróem.

Palavras-chave: Desigualdade Social; Exclusão; Psicologia Social Crítica; Políticas Públicas.

\section{THE IMPACTS OF SOCIAL VULNERABILITY ON THE CONSTRUCTION OF SUBJECTIVIY}

\begin{abstract}
This research had as a main goal to conduct a study on the concept of social vulnerability and its impacts on the construction of subjectivity, using bibliographic reviews that could cover the years 1990 and 2020. The discussion was based on Critical Social Psychology, it made possible to visualize the context of social vulnerability as a marker of subjectivities. Therefore, we treat the concepts of vulnerability and subjectivity based on their diversity of understandings, where we work both in their etymologies, considering their multiple possibilities of reading, as well as their applications from the perspective of Critical Social Psychology. Therefore, we conclude that the relationship of social vulnerability in the construction of human subjectivities is related. since it was possible to observe the multi-interactions with which the phenomena "vulnerability" and "subjectivity" are built.
\end{abstract}

Keywords: Social Inequality; Exclusion; Critical Social Psychology; Public policy.

\footnotetext{
${ }^{1}$ Endereço eletrônico de contato: luiz.cardoso@prof.una.br

Recebido em 25/04/2021. Aprovado pelo conselho editorial para publicação em 20/07/2020.
} 


\section{LOS IMPACTOS DE LA VULNERABILIDAD SOCIAL EN LA CONSTRUCCIÓN DE SUBJETIVIDAD}

\section{RESUMEN}

Esta investigación tuvo como objetivo principal realizar un estudio sobre el concepto de vulnerabilidad social y sus impactos en la construcción de la subjetividad, utilizando revisiones bibliográficas que podrían cubrir los años 1990 y 2020. La discusión se basó en la Psicología Social Crítica, hizo posible visualizar el contexto de vulnerabilidad social como marcador de subjetividades. Por lo tanto, tratamos los conceptos de vulnerabilidad y subjetividad en función de su diversidad de comprensión, donde trabajamos tanto en sus etimologías, considerando sus múltiples posibilidades de lectura, como sus aplicaciones desde la perspectiva de la Psicología Social Crítica. Por lo tanto, concluimos que la relación de vulnerabilidad social en la construcción de subjetividades humanas está relacionada. ya que fue posible observar las múltiples interacciones con las cuales se construyen los fenómenos "vulnerabilidad" y "subjetividad".

Palabras clave: Desigualdad social; Exclúsion; Psicología social crítica; Política pública.

\section{INTRODUÇÃO}

O presente trabalho buscou compreender os impactos da vulnerabilidade social na construção da subjetividade, aproximando o olhar da Psicologia Social junto a estes fenômenos. Ao observarmos a complexidade do conceito de vulnerabilidade social e, pesquisando as produções a respeito deste tema nas últimas três décadas, destaca-se uma necessidade de fomentar, na academia, um intento de pesquisa maior no campo da vulnerabilidade e em todas as suas complexas facetas, especialmente no campo da Psicologia, pois, evidencia-se que, nas últimas décadas, as produções a respeito do tema se atentam mais à conceitualização deste do que propriamente a sua práxis. Para tanto, pretendemos trazer a compreensão dos conceitos aqui trabalhados tendo como base, principalmente, os estudos da Psicologia Social Crítica, que nos auxiliará a melhor depreender a influência social-histórica na formação subjetiva dos indivíduos, bem como na compreensão dos pontos cruciais nos quais se deram as vulnerabilidades sociais instauradas nas diversas camadas da sociedade.

Com a pretensão de descrever o impacto da vulnerabilidade social na construção da subjetividade, Sawaia (2001) nos fornece uma importante base para pensar o fenômeno da vulnerabilidade, ao tratar da dialética inclusão/exclusão, onde é exposto que se precisa, nas ciências sociais, avançar no estudo dos mecanismos de exclusão, abordando de forma Rev. Psicol Saúde e Debate. Jul., 2021:7(2): 48-65. 
episteme o sujeito, ao colocá-lo no centro da análise considerando as mais diversas formas de existência e como estas são impactadas por fenômenos sociais de exclusão, a partir de suas repercussões nos espaços de convivência. Tais preceitos nos convidam a visualizar o fenômeno da vulnerabilidade social em uma relação dialética com o sujeito, ao entender que este sujeito constrói sua subjetividade também nessa relação multi facetada com o meio (Aita \& Facci, 2011).

Da mesma forma, discutimos ao longo da pesquisa a noção de exclusão e os impactos deste conceito na realidade brasileira em toda sua constituição, aproximando-a do termo vulnerabilidade social e demarcando a relevância de pensar os mecanismos de exclusão a partir de uma perspectiva sócio-histórica (Sawaia, 2001).

Assumindo a amplitude do conceito "vulnerabilidade social", não se restringindo à ideia de pobreza, como suscitado a partir das análises sócio-históricas do fenômeno, expandimos nossa discussão a partir de elucidações sobre o termo "capital social", que levantamos como contraponto aos contextos de vulnerabilidade trabalhados, que diz sobre a definição de fatores de risco e de proteção de um território; as relações de confiabilidade ali estabelecidas; fatores econômicos, etc. (Gustin, 2005).

Além de trabalhar os preceitos já mencionados, abordaremos o conceito de subjetividade, concebida aqui como um produto social que acompanha a historicidade do sujeito. Compreendemos também a atuação da psicologia na criação de políticas públicas que possam trabalhar, efetivamente, às subjetividades coletivas. As circunstâncias as quais uma sociedade perpassa, implicam diretamente na construção da subjetividade do sujeito, uma vez que a compreensão desse fenômeno se dá de diversas formas, pois carrega em si uma gama de complexidades em sua história. Ao nascer, cada sujeito toma para si alguns referenciais sociais para embasar a sua construção individual, tal construção é também coletiva, uma vez que nascemos inseridos em contextos já pré-construídos, com formatos estabelecidos no campo da objetividade. A desigualdade social promove nestes indivíduos um grande impacto em suas construções coletivas, visto que suas potencialidades são incapacitadas (Gonçalves, 2010).

Conceitualizar a subjetividade nos permitiu adentrar no campo da "dimensão subjetiva da desigualdade social", e este nos proporcionou uma compreensão de como os sujeitos, coletivamente, são diretamente influenciados pelo contexto vulnerável o qual estão inseridos. $O$ indivíduo, como ser social, é atravessado por uma série de fatores externos que exercem influências direta na sua formação; tais fatores são marcas sociais que se configuram por meio dos processos culturais, como as leis, regras e ideologias de determinada população. Os sujeitos inseridos em um mesmo espaço, tendem a receber os mesmos impactos do mundo Rev. Psicol Saúde e Debate. Jul., 2021:7(2): 48-65. 
objetivo, sendo estes impactos potencializadores para a sua formação social (Bock \& Gonçalves, 2005 citado por Nascimento, Sarubbi, \& Souza, 2009).

Para se lograr êxito em alcançar os interesses que motivaram a construção deste trabalho, procedemos da seguinte forma: (1) investigar o conceito de vulnerabilidade social; (2) descrever a construção da subjetividade sob a perspectiva da Psicologia Social Crítica; (3) analisar a dimensão subjetiva da vulnerabilidade social; (4) compreender as políticas públicas voltadas à diminuição de desigualdades e promoção de capital social e observar os impactos da promoção do capital social em contextos de vulnerabilidade. Assim, esta pesquisa possui o objetivo de analisar e problematizar, através da literatura específica, como aparecem e se perpetuam os mecanismos de exclusão em contextos de vulnerabilidade social, considerando os impactos que estes geram nas subjetividades individuais e coletivas, além de ponderarmos sobre quais ferramentas estão dispostas à comunidade para o enfrentamento deste fenômeno.

\section{MÉTODO}

A presente pesquisa trata-se de um estudo qualitativo a partir do método de revisão bibliográfica. Partindo da premissa de que, como apontam Sabadini, Sampaio e Koller (2009, p.134) "Na abordagem qualitativa, os pesquisadores procuram, a partir de observações e de análises abertas, descobrir as tendências e os processos que explicam o como e o porquê dos fenômenos.", escolhemos este tipo de abordagem para podermos nos aprofundar no estudo dos fenômenos a serem analisados, dialogando com as bibliografias existentes. E, a partir da revisão bibliográfica, definida por Gil (2002, p.44) como uma pesquisa bibliográfica que "é desenvolvida com base em material já elaborado, constituído principalmente de livros e artigos científicos. Embora em quase todos os estudos seja exigido algum tipo de trabalho dessa natureza, há pesquisas desenvolvidas exclusivamente a partir de fontes bibliográficas.", pretendemos analisar, de forma minuciosa, estudos já existentes que, também, possam contribuir para a originalidade desta pesquisa a partir da nossa temática e os referenciais utilizados.

Para se chegar aos resultados, recorremos a bases bibliográficas; livros e artigos buscados nas bases de dados científicas, tais quais: Scielo e Pepsic. Foram utilizados os seguintes descritores: Vulnerabilidade, Subjetividade e Psicologia. Os artigos encontrados foram selecionados a partir dos seguintes critérios: publicações realizadas entre os anos de 1990 a 2020, estar em Português (Brasil), temas que abordem vulnerabilidade social; subjetividade segundo a perspectiva da Psicologia Social Crítica e as Políticas Públicas. 


\section{DESENVOLVIMENTO}

\subsection{Vulnerabilidade social enquanto conceito}

Ao tratar da vulnerabilidade social como um objeto fundante de análise para a pesquisa, faz-se necessário recorrer a este termo a partir de suas diversas possibilidades de desdobramento ao considerarmos seu ímpeto prático, como: a etimologia do termo e a importância de situá-lo sócio-historicamente; a relação e aproximação da vulnerabilidade e o conceito "exclusão social" e a historicidade do conceito no Brasil, visando elucidar o impacto histórico dos mecanismos de exclusão neste território.

Partindo da análise etimológica do termo, recuperamos o ensaio das autoras Carmo e Guizard (2018), onde é destrinchada a "vulnerabilidade" a partir do Latim por intermédio das palavras "vulnerare" e "bilis" que, segundo as autoras, representavam uma condição inerente do ser humano, "naturalmente necessitado de ajuda", dispondo sobre os danos potenciais vinculados à mera existência humana, em uma perspectiva individual. Contudo, tal interpretação advinda da origem do termo ainda não consegue dizer sobre a materialidade das vivências humanas, que possuem diversos potenciais atravessadores, como as desvantagens em mobilidade social, cidadania fragilizada, distribuição desigual de políticas públicas, entre outros fatores que compõem a extensão do termo vulnerabilidade em uma perspectiva sóciohistórica.

Assim, expandimos a discussão sobre vulnerabilidade a partir da inclusão do termo "social" visando contemplar tais dimensões citadas. Dessa forma, podemos avançar nas análises tocantes à concepção do termo a partir dos seus impactos históricos e contextuais.

Deste modo, para tratarmos da vulnerabilidade social enquanto práxis, agora, considerando sua aproximação terminológica da noção de "exclusão social", recorremos à discussão levantada pela Wanderley (2001), no livro "As Artimanhas da Exclusão - Análise Psicossocial e Ética da Desigualdade Social" ao classificar o termo exclusão enquanto um paradigma social em construção, que aparece como uma pauta mais consolidada para análises a partir da década 90 (noventa) acompanhando as intensas modificações dos contextos, especialmente no recorte laboral, onde o capitalismo aparece como um importante fenômeno atravessador.

Nessa perspectiva, Xiberras (1993, citado por Wanderley, 2001, p. 17) trabalha com a exclusão em aproximação com a vulnerabilidade social dentro deste paradigma a partir de um recorte ocidental, onde, para a autora: "excluídos são todos aqueles que são rejeitados de nossos mercados materiais ou simbólicos, de nossos valores"; assim, dizer que existe a Rev. Psicol Saúde e Debate. Jul., 2021:7(2): 48-65. 
marcação do espaço de exclusão nos convida a pensar sobre a não ocupação de um lugar por parte dos sujeitos inseridos em contextos de vulnerabilidade social, pois thes é vedada a participação em contextos materiais, geográficos, simbólicos.

Portanto, partimos da dialética de inclusão/exclusão ou "inclusão perversa" como trabalhada por Sawaia (2001), para pensarmos o fenômeno multifacetário da vulnerabilidade social, a partir dessa definição de um lugar que não é amplamente concedido, onde a exclusão passa a ser lida como um "descompromisso político com o sofrimento do outro", marcando sua crítica aos modelos minimalistas de inclusão; o capitalismo enquanto um sistema que exclui para incluir e as configurações sociais que não se preocupam em considerar as complexidades que atravessam os sujeitos e lhes retira de determinados locais, como a já mencionada distribuição desigual de políticas públicas enquanto um fator de exclusão dos mercados materiais, como o acesso a bens básicos: educação, saúde pública, entre outros fatores.

Expandindo as ideias expostas a respeito das estruturas promotoras de exclusão, faz-se necessário aprofundarmo-nos no capitalismo enquanto sistema para destrincharmos o seu papel frente aos contextos de vulnerabilidade social. Assim, Silva (2001) aponta que a desigualdade social que, para a autora, conduz os sujeitos a situações de vulnerabilidade social, aparece como uma marca do capitalismo. Nesse sentido, é sustentado que o sistema capitalista, com a peculiaridade de ter em sua gênese a exploração de sujeitos por outros sujeitos, já possui um escopo natural de exclusão, expressa na divisão social de classes, que se torna bem demarcada dentro do capitalismo; ainda, ao recuperarmos as análises de Marx e Engels (1998, p.7), onde é apontado que "A história de todas as sociedades até o presente é a história das lutas de classes.", observamos, para além da constituição histórica da humanidade que já aponta para a luta de classes, a vivência em um modelo econômico potencializador da divisão social de classes que implica, por conseguinte, em experiências de vulnerabilidade social expandidas.

Isto posto, podemos avançar na leitura da vulnerabilidade social enquanto fenômeno em um recorte contextual tocante a esta pesquisa: os impactos dos mecanismos de exclusão e propagação de vulnerabilidade social no Brasil em um entendimento sócio-histórico. Verás (2001) discorre sobre o tema expondo que não cabe pensar exclusão/vulnerabilidade social a partir de experiências em outros contextos quando se pretende analisar este fenômeno no Brasil, partindo da perspectiva aqui trabalhada de que, para lidarmos com a materialidade do fenômeno, é preciso considerar as vivências subjetivas em cada contexto. Assim, a autora expõe que, apesar da relevância dos debates levantados em um recorte europeu a partir da exclusão como um paradigma, estas discussões não poderiam dizer sobre um contexto como o brasileiro, que possui diversos processos sociais excludentes, tais como: o passado Rev. Psicol Saúde e Debate. Jul., 2021:7(2): 48-65. 
escravocrata e seus desdobramentos com a desigualdade racial; a exclusão dos indígenas do convívio social; o exercício de cidadania fragilizado, especialmente no contexto da ditadura militar, entre outros fatores que compõem nossa trajetória histórica marcando sujeitos e contextos.

Por conseguinte, Verás (2001) amplia o debate a respeito da vulnerabilidade social no país discorrendo sobre seus momentos históricos e seus mecanismos de exclusão, nos chamando atenção, especialmente, a relação estabelecida na análise entre os sujeitos já marginalizados e a inclusão perversa ou precária, aqui já discutida, provocada pelo capitalismo e suas políticas Neoliberais a partir da análise estabelecida por Martins, (1997), onde é analisada a postura das classes dominadas frente a um possível conflito social na relação com o opressor, por estarem adequados ao funcionamento social, como expõe:

[...] no Brasil, políticas econômicas atuais, que poderiam chamar-se neoliberais, acabam por provocar, não políticas de exclusão e, sim, políticas de exclusão precária e marginal, ou seja, incluem pessoas nos processos econômicos, na produção e na circulação de bens e serviços estritamente em termos daquilo que é racionalmente conveniente e necessário à mais eficiente (e barata) reprodução do capital. (Martins, 1997, p. 20).

Dessa forma, temos que os processos de exclusão social como promotores de vulnerabilidade social marcam o contexto brasileiro em uma análise diacrônica, seja como na contemporaneidade, em provocar um sentimento de pertencimento aos sujeitos incluindo para excluir, ou mesmo no tocante às experiências históricas do Brasil como exposto no texto (Sawaia, 2001).

\subsection{Subjetividade: uma análise pautada na perspectiva da Psicologia Social Crítica}

O conceito de subjetividade tem sido abordado durante os anos por muitos estudiosos, sendo compreendido de numerosas formas. Falaremos aqui da subjetividade pautada na perspectiva da Psicologia Social Crítica, entendo tal fenômeno como singularidade do indivíduo e, também, como produto social. 
A abordagem histórico-cultural é concebida pela Psicologia Social Crítica como sendo a área da psicologia que observa como ocorre a relação dos seres humanos com os processos históricos e sociais que atravessam essa relação (sujeito e objeto), também compreendida na abordagem como uma relação dialética. Tal relação, que é idiossincrática, ocorre de forma natural e é intrínseca a qualquer sociedade, pois ela está circunscrita na base das relações humanas, como a transmissão de conhecimento e a comunicação. A transmissão de conhecimento e a comunicação podem ocorrer de diversas formas, sejam elas verbais, corporais ou através de algum meio que possibilite externalizar as manifestações internas de cada indivíduo com o mundo real e objetivo. Entender esses dois conceitos torna-se um dos pontos cruciais para depreender a noção de subjetividade trabalhada na Psicologia Social, visto que, passado e presente, são dois polos que se interconectam através dos processos de transmissão de conhecimento e comunicação, processos esses que serão apropriados por gerações futuras para a assimilação da contemporaneidade. Todo esse movimento resulta no que compreendemos como história, o estudo das ações dos indivíduos no decorrer dos tempos. Aita e Facci (2011) nos clareia esta discussão da seguinte maneira:

[...] o sujeito desenvolve as características especificadamente humanas à proporção que internaliza o trabalho social, o modo de pensar e agir cristalizado na sociedade na qual está inserido. Sem o processo de transmissão de conhecimentos e de comunicação, seria impossível a continuidade do processo histórico, visto que as gerações seguintes não teriam acesso ao desenvolvimento histórico-cultural da humanidade (Aita \& Facci, 2011, p. 35).

Apesar de sua polissemia, em geral a compreensão do termo subjetividade é entendida como uma característica individual, algo que diferencia uma pessoa da outra. Ela é construída a partir da relação sujeito e ambiente (ambiente também entendido como objetividade):

Geralmente, subjetividade é entendida como aquilo que diz respeito ao indivíduo, ao psiquismo ou a sua formação, ou seja, algo que é interno, numa relação dialética com a objetividade, que se refere ao que é externo. É compreendida como processo e resultado, algo que é amplo e que constitui a singularidade de cada pessoa (Silva, 2009, p.170).

Segundo Bock (2004, p.6) “... o fenômeno psicológico deve ser entendido como construção no nível individual do mundo simbólico que é social...”. Bock nos traz a dimensão subjetiva como um fenômeno que se apresenta no sujeito por meio de sua relação com o Rev. Psicol Saúde e Debate. Jul., 2021:7(2): 48-65. 
mundo, ambiente; tal dimensão, que é simbólica, só é possível mensurar através de uma interação com a objetividade, "... o fenômeno deve ser visto como subjetividade, concebida como algo que se constituiu na relação com o mundo material e social, mundo este que só existe pela atividade humana. Subjetividade e objetividade se constituem uma à outra sem se confundirem" (Bock, 2004, p. 6).

A subjetividade também pode ser demarcada como um fator coletivo, um jaez que marca as sociedades a partir de sua historicidade. Uma sociedade marcada por determinada característica, influencia diretamente a forma como os indivíduos que nela existem se percebem e são percebidos; tais indivíduos serão influenciados fortemente pelo determinismo histórico o qual fazem parte, todas as expectativas e oportunidades destes sujeitos, que se fazem existir em uma sociedade capitalista e globalizada, irão perpassar pelas características que a objetividade do mundo externo lhes proporcionar no mundo interno. A complexidade que se dá a existência de um indivíduo, não pode ser compreendida de forma completa sem considerar o meio o qual ele atua e como esse contexto atua sobre ele, assim como explana Bock:

[...] falar do fenômeno psicológico é obrigatoriamente falar da sociedade. Falar da subjetividade humana é falar da objetividade em que vivem os homens. A compreensão do "mundo interno" exige a compreensão do "mundo externo", pois são dois aspectos de um mesmo movimento, de um processo no qual o homem atua $e$ constrói/modifica o mundo e este, por sua vez, propicia os elementos para a constituição psicológica do homem. (Bock, Gonçalves, \& Furtado, 2001, p.22)

Diante disso, podemos compreender que todo processo que atravessa o sujeito, perpassa por um contexto amplo de comutação. O ser humano é atuante em sua história, ele modifica e é modificado, e tais transformações repercutem diretamente em sua formação de identidade. Para compreender um determinado contexto, e como este contexto se forma, devese analisar a dimensão subjetiva a qual ele faz parte, como se manifestam os fenômenos psicológicos dos indivíduos que constituí essa realidade, como nos elucida Gonçalves:

[...] entende-se por dimensão subjetiva aspectos decorrentes da presença, nos fenômenos da realidade, de indivíduos que são sujeitos. Trata-se de um enfoque que, como em toda a psicologia, aborda os fenômenos psicológicos, portanto individuais. Mas aborda-os enquanto subjetividade constituída na relação com a objetividade. Por isso nunca são fenômenos apenas individuais; são necessariamente sociais e históricos. E são próprios de indivíduos humanos que se constituíram historicamente como sujeitos (Gonçalves, 2010, p.24). 
O sujeito constrói sua história e, da mesma forma que a constrói, também é construído por ela. Todo esse processo de troca gera uma carga histórica que repercutirá na formação de identidade das pessoas que estão inseridas em determinados contextos, fazendo com que estas repliquem tais comportamentos - formas de pensar e ver o mundo -, ou com que elas recriem uma nova perspectiva/história, a partir do que Ihes são apresentados. Segundo Gonçalves (1998, p.136) “... as ideias e conhecimentos produzidos pelo homem em um determinado momento histórico refletem a realidade desse momento histórico, ou seja, nosso pressuposto é de que a origem das ideias produzidas socialmente está na base material da sociedade.", a ideia, compreendida aqui como um fenômeno que se manifesta através da subjetividade, se modifica de acordo com a época. Podemos observá-la como um traço que marca, não somente cada indivíduo, cada peculiaridade que o envolve, mas também como um marco social, um determinante que modela as formas de se manifestar um sujeito, determinado contexto:

[...] a categoria subjetividade, tomada simultaneamente como experiência humana, signo e conceito teórico pode mostrar essa relação construída no movimento histórico. Enquanto experiência humana, a subjetividade modifica-se e aparece de diferentes formas ao longo da história humana; enquanto signo, designa essa experiência, modificando-se juntamente com ela, ao mesmo tempo permitindo a expressão dessa experiência e transformando-a; enquanto signo que ganha o estatuto de um conceito teórico, aparece no bojo do desenvolvimento da ciência na modernidade, mais especificamente com a psicologia, embora não apareça desde o início formal dessa ciência como um conceito explícito. (Gonçalves, 1998, p.136)

A subjetividade pode se tornar uma marca coletiva e essa marca, carregada de uma gama de estereótipos, é o que acaba por definir e dividir determinadas camadas populares; a vulnerabilidade quanto obra das desigualdades advindas dos diversos processos sóciohistórico que uma sociedade perpassa, pode determinar até onde cada sujeito pode chegar, até onde cada indivíduo se torna criador de sua própria existência e, concomitantemente, sofre os impactos do contexto que está inserido (Gonçalves, 1998).

\subsection{A dimensão subjetiva da vulnerabilidade social}

É por meio da relação dialética com o mundo objetivo que a realidade de cada sociedade é construída. É dessa relação mútua que o processo de subjetivação acontece; os indivíduos de uma sociedade estão a todo momento criando e sendo criados por esta dimensão subjetiva que tem como premissa toda a história percorrida por seus antecessores. 
Em um contexto de vulnerabilidade, essa realidade não é diferente; os sujeitos são construídos fielmente por toda historicidade que aquele contexto carrega. É aí que a dimensão subjetiva da desigualdade está instaurada, é a partir dessa historicidade que diversas massas sociais são moldadas (Nascimento, Sarubbi, \& Souza, 2009).

O sujeito é um ser social e, como tal, ao nascer, é enquadrado, integrado, aculturado, pelos costumes e historicidades o qual está imerso em determinado espaço geográfico (movimento dialético). O indivíduo, ser social, apreende através de suas possibilidades de escolhas e interação do subjetivo - pensamento, forma que assimila o conteúdo interno-, com o objetivo - a cultura, política, educação. Tal unicidade de valores e conteúdo, faz com que cada sujeito se desenvolva conforme as condições subjetivas que o espaço o qual está imerso possa Ihe proporcionar. Essa imersão é inerente ao indivíduo, todos estamos sujeitos a modificar e sermos modificados pela dimensão subjetiva que é externa a nós (Bock \& Gonçalves, 2005 citado por Nascimento, Sarubbi, \& Souza, 2009).

Quando falamos de subjetividade, estamos referindo-nos ao fato de que o processo de construção do mundo objetivo tem uma dimensão simbólica (...) [uma] configuração - que nunca fica pronta - do processo de transformação do mundo, no âmbito do sujeito. (...) No entanto, esses registros [simbólicos], além de estarem no campo da subjetividade do sujeito, também estão no campo coletivo, pois se objetivam como leis, valores, regras, significados, ideologias, teorias, ciência e discursos. Assim, toda a realidade social tem uma dimensão subjetiva (Bock \& Gonçalves, 2005 citado por Nascimento, Sarubbi, \& Souza, 2009, p.17).

Este processo de construção do mundo objetivo, segundo Bock e Gonçalves (2005), citado por Nascimento, Sarubbi e Souza, (2009), exerce grande influência na subjetividade coletiva, vez que os processos que constituem uma sociedade, como as leis, as regras, ideologias, políticas públicas que envolvem tais sujeitos, são influenciados e influenciadores dos diversos processos que induz o crescimento das desigualdades sociais. Todas essas contingências contribuirão para a formação de uma dimensão desigual de vivências, experiências e formas de enxergar o mundo. A dimensão subjetiva da vulnerabilidade social está diretamente ligada aos recursos que determinados indivíduos tiveram acesso para o desenvolvimento de suas potencialidades, ou seja, uma possibilidade de desenvolvimento de cada indivíduo; tal como nos é elucidado abaixo:

A produção individual de sentido tem sua gênese no encontro singular de um sujeito com a experiência social concreta. Esse encontro se produz em várias dimensões: o sujeito vivencia e se representa em nível consciente vários elementos da experiência e associados a ela, sobre os quais nos pode falar, elementos que podem ou não ser Rev. Psicol Saúde e Debate. Jul., 2021:7(2): 48-65. 
portadores de sentido. Por sua vez, o sujeito experimenta emoções que não consegue explicar e sobre as quais, às vezes, nem tem consciência. Ambos os níveis de expressão de sentido subjetivo de experiência integram em uma unidade indissolúvel a história do sujeito e o contexto social da experiência subjetivada, provocando formas diferentes de conduta, emoções e representações que acompanham a posição do sujeito diante da situação." (Gonzalez Rey, 2004 citado por Nascimento, Sarubbi, \& Souza, 2009, p. 19).

Partindo de tais análises, Jodelet (2001) nos convida a pensar na intercessão entre a noção de exclusão e a materialidade das vivências que podem ser observadas nas produções individuais e coletivas da subjetividade. É discutido em qual nível os processos que levam a exclusão, tais como: o racismo, desemprego, incapacidades físicas/mentais etc, podem se aproximar da exclusão social enquanto mecanismo, onde só seria possível visualizarmos no nível de interação de sujeitos em instâncias individuais ou grupais, como a autora expõe:

Com efeito, a exclusão induz sempre uma organização específica de relações interpessoais ou intergrupos, de alguma forma material ou simbólica, através da qual ela se traduz: no caso da segregação, através de um afastamento, da manutenção de uma distância topológica; no caso da marginalização, através da manutenção do indivíduo à parte de um grupo, de uma instituição ou do corpo social; no caso da discriminação, através do fechamento do acesso a certos bens ou recursos, certos papéis ou status, ou através de um fechamento diferencial ou negativo. (Jodelet, 2001, p. 53).

Dessa forma, temos na vulnerabilidade social um campo amplo de pesquisa e compreensão, entendendo as complexidades que este fenômeno carrega, especialmente ao tratarmos de sua aproximação com as mais diversas formas de manifestação dos sujeitos expressas pela subjetividade. Assim, as leituras frente à vulnerabilidade social geram um contexto que chamamos de potencializador, imerso em diversas conjunturas sociais que exercem uma função fundamental na formação dos sujeitos. Compreender o campo dimensional que se instaura nas desigualdades sociais aparece como um ponto central para entendermos como a construção subjetiva de um indivíduo é modificada em contato com o espaço o qual ele está inserido. Tais elucidações ajudam a depreender de qual forma esse indivíduo, imerso em um contexto de fragilidade social, será potencialmente desenvolvido e quais os recursos estão sendo disponibilizados ou não para a diminuição dos impactos negativos que este sujeito estará sendo municiado, como sustentado abaixo: 
A desigualdade está tomada aqui, então, como um fenômeno social que caracteriza nossa vivência em sociedade e que possui uma dimensão, que aqui denominamos dimensão subjetiva e que se refere a um conjunto de experiências psicológicas do sujeito. O conjunto destas expressões de sentido nos permitirá indicar aspectos que compõem estas vivências: são significados, emoções, imagens, conceitos que se estruturam de modo a dar, à experiência, um significado pessoal e que no coletivo, compõe a dimensão subjetiva da desigualdade social (Nascimento, Sarubbi, \& Souza, 2009, p. 20).

O impacto da vulnerabilidade social, trabalhada enquanto desigualdade, na subjetividade coletiva aparece como um fenômeno complexo de ser analisado, posto que tais compreensões atravessam uma série de fatores sociais, históricos e culturais que estão enraizados em diversos espaços. Compreende-se que cada indivíduo receberá o impacto desta desigualdade de forma distinta, pois ocorre um choque da subjetividade individual e a subjetividade social.

\subsection{Políticas públicas e sua importância na diminuição das}

\section{vulnerabilidades sociais}

Após traçarmos relações entre a vulnerabilidade social e a subjetividade, pretendemos abordar a importância que as políticas públicas exercem na diminuição das vulnerabilidades sociais, bem como ressaltar o papel do Estado na criação de outros mecanismos de proteção que possam contribuir nesta diminuição. Não obstante, abordaremos também seu papel no favorecimento da participação popular na construção de tais políticas enquanto práxis. Tencionamos perpassar, também, quais impactos estas políticas exercem nas construções das subjetividades coletivas.

As políticas públicas são pensadas como ferramentas para que o estado possa atender as necessidades da sociedade. Em outras palavras, "...as Políticas Públicas são a totalidade de ações, metas e planos que os governos (nacionais, estaduais ou municipais) traçam para alcançar o bem-estar da sociedade e o interesse público" Serviço Brasileiro de Apoio às Micro e Pequenas Empresas [SEBRAE] (2008, p.5). Nota-se que, diante de um quadro em que determinado contexto encontra-se em condição de vulnerabilidade, o Estado e suas repartições governamentais, deve assumir um papel crucial para a modificação destas realidades. Tendo como uma das finalidades a diminuição das desigualdades sociais, as políticas públicas, quando criadas, passam por uma análise que determinará o grau de Rev. Psicol Saúde e Debate. Jul., 2021:7(2): 48-65. 
prioridade destas, caso atenda ao interesse público, estas políticas serão selecionadas e implementadas de tal forma que possam atender, senão de forma integral, ao menos de forma parcial à solicitação. As necessidades de determinados grupos, muitas vezes podem não ser contempladas em sua totalidade, uma vez que a implementação delas dependem de outros recursos governamentais.

Compreendidas as diversas demandas e expectativas da sociedade, ele fará a seleção de prioridades para, em seguida, oferecer as respostas. As respostas nunca atenderão às expectativas de todos os grupos. Alguns grupos serão contemplados, outros não. Para os grupos contemplados o governo terá de formular e desenvolver ações para buscar atender suas expectativas, integral ou parcialmente. Quando o governo busca atender as principais (na sua percepção) demandas recebidas, diz-se que ele está voltado para o interesse público (ou seja, para o interesse da sociedade). Ao atuar na direção do interesse público, o governo busca maximizar o bem estar social (SEBRAE, 2008, p.7).

Compreender como se formam as políticas públicas e para quem elas são destinadas, é de suma importância para que possamos analisar o grau de efetividade que estas políticas, já instauradas ou não, alcançarão ou já estão alcançando na sociedade. Uma vez implementada uma política assistencial, esta deverá garantir àqueles que ela cobre, o mínimo de condições possíveis para se fazer cumprir suas diretrizes assistenciais.

Assim, retomando o interesse dessa pesquisa quanto ao recorte junto aos mecanismos de exclusão - que fomentam a vulnerabilidade social - analisados no contexto brasileiro, temos um importante avanço histórico frente às políticas de assistência instauradas no país, especialmente a partir da criação da Lei Orgânica de Assistência Social (LOAS), que surge após as disposições a Constituição Federal de 1988, "equiparando os direitos de assistência social com os direitos de acesso a saúde e a previdência social" (LOAS, 2013, p. 7). Dessa forma, a vulnerabilidade social enquanto paradigma passa a ser considerada a nível estatal, a partir da premissa de garantirmos um sistema de seguridade social para o brasileiro.

Isto posto, lidar com este paradigma surge como um importante desafio /compromisso para o Estado, onde falar de construção de políticas públicas, especialmente no campo da assistência, implica em uma relação com seus atores próprios (estatais) além da participação popular (SEBRAE, 2008). Assim, buscando a interlocução entre a construção de Políticas Públicas com os impactos da vulnerabilidade social na subjetividade, escolhemos destinar nossos olhares a programas assistenciais que partam da premissa da diminuição de desigualdades através dos mecanismos de proteção existentes na própria comunidade, Rev. Psicol Saúde e Debate. Jul., 2021:7(2): 48-65. 
engajando os sujeitos no processo de construção da política, especialmente a Política de Prevenção Social à Criminalidade de Minas Gerais, com o Programa Mediação de Conflitos (PMC), visando a exemplificação de práticas efetivas dentro do estado no que diz respeito a esta temática.

Sendo assim, o PMC nos chama atenção não somente por trabalhar em contextos com alto índice de vulnerabilidade social por intermédio do seu recorte territorial; baixo acesso a direitos, entre outros fatores listados no livro "Mediação e Cidadania", que visam a elaboração de ações efetivas de mediação de conflitos; como, também, em sua gênese metodológica que, para Ferrari et al. (2010, p. 11), "defende a constituição de capital social como a única forma de minimizar os efeitos da exclusão social e da pobreza em países de desenvolvimento periférico, marcado pelas desigualdades sociais".

Dessa forma, faz-se importante a contextualização do Capital Social a fim de relacionarmos tal conceito como um contraponto à ideia de vulnerabilidade social tratada nesta pesquisa. Portanto, para Gustin (2005), Capital Social pode ser definido como "Existência de relações de solidariedade e confiabilidade entre indivíduos, grupos e coletivos, inclusive a capacidade de mobilização e organização comunitárias, traduzindo um senso de responsabilidade da própria população sobre seus rumos e sobre a inserção de cada um no todo" (Gustin, 2005, p. 11).

Destarte, observa-se que, aqui, como defendem Leandro e Cruz (2014), o Programa não somente reconhece os atores necessários para sua construção (aproximando-se da população), mas, também, parte do princípio de que para minimizarmos, ou mesmo rompermos em alguma instância com os impactos gerados pela vulnerabilidade social, é necessário fomentarmos, a priori, a mobilização popular; o fortalecimento do exercício da cidadania; o enfrentamos às violências, entre outros fatores, que possam aumentar o capital social préexistente.

A partir das análises do que é basilar ao programa e observando a importância do fomento ao Capital Social junto ao PMC, avançamos com as reflexões propostas na interface das Políticas Públicas e a diminuição das vulnerabilidades sociais, onde pudemos recuperar o conceito de subjetividade coletiva já trabalhado neste texto, considerando que, ao lidarmos com a efetividade das Políticas Públicas que promovem o enfrentamento ao fenômeno da vulnerabilidade social, não se ataca só o problema da forma como ele se apresenta a posteriori; pondera-se também a respeito da construção das subjetividades dos sujeitos presentes nos contextos vulneráveis, ao assumir que, ao traçar movimentos que buscam a alteração da realidade material, formam-se novos sujeitos, novas subjetividades, a partir da interseção com o mundo simbólico, que é social (Bock, 2004).

Rev. Psicol Saúde e Debate. Jul., 2021:7(2): 48-65. 


\section{CONSIDERAÇÕES FINAIS}

Tencionamos construir no decorrer desta pesquisa, uma análise dos impactos dos contextos de vulnerabilidade social na construção da subjetividade. Depreender como se dá a construção de um contexto de vulnerabilidade nos possibilitou entender as complexas facetas que este fenômeno implica na constituição dos sujeitos, tendo como base uma leitura sóciohistórica que permitiu-nos entender a dialética social a qual os indivíduos estão submetidos.

Um dos pontos fundamentais para a construção desta pesquisa, foi falar do lugar da psicologia, que nos permitiu expandir o olhar para os fenômenos trabalhados, deslocando-a do seu local hegemônico (clínica tradicional) e possibilitando uma análise contemporânea, onde assume-se a relevância do contexto (mundo objetivo) na formação dos sujeitos ali inseridos. Trabalhar com conceitos como vulnerabilidade e subjetividade, concedeu-nos uma visão ampliada dos indivíduos, posto que estes influenciam e são influenciados pelo contexto o qual estão imersos, não podendo assimilar tais fenômenos sem antes compreender todos os aspectos que o envolve.

Pôde-se observar, também, os impactos significativos que as Políticas Públicas, quando efetivas, exercessem na construção de subjetividades, uma vez que estas promovem e fomentam mecanismos que podem amenizar cenários de vulnerabilidades sociais. Para a criação dessas políticas, torna-se importante a participação popular junto ao Estado na construção destas, uma vez que os indivíduos que vivenciam as vulnerabilidades em seu contexto, possuem maior poder para promover um olhar crítico para este local.

Isto posto, concluímos que a relação da vulnerabilidade social na construção das subjetividades humanas, se dão de forma análoga, pois nos foi possível, por meio de estudos minuciosos e análises textuais, depreender as multi-interações com as quais os fenômenos "vulnerabilidade" e "subjetividade" se constroem. Desta relação, são produzidos na sociedade fatores prejudiciais para o desenvolvimento subjetivo dos sujeitos, haja vista que as subjetividades, quando construídas dialeticamente com o contexto objetivo, são afetadas significativamente por esta construção. Da mesma forma, ao trazermos a análise do "capital social" como contraponto ao conceito de vulnerabilidade social trabalhado, inferimos que fatores como o fortalecimento do exercício da cidadania, a mobilização social, alinhados com o compromisso estatal de atuar no enfrentamento da vulnerabilidade, impactam significativamente a construção de subjetividades individuais e coletivas.

Rev. Psicol Saúde e Debate. Jul., 2021:7(2): 48-65. 


\section{REFERÊNCIAS}

Amaral, A. F., \& Borges, M. A. R. (2015). A desigualdade social e suas influências na subjetividade contemporânea. Psicologia e Saúde em Debate, 1(2), pp. 1-19. Recuperado em 23 de setembro de 2019, de http://psicodebate.dpgpsifpm.com.br/index.php/periodico/article/view/19/11

Aita, E. B., \& Facci, M. G. D. (2011). Subjetividade: uma análise pautada na Psicologia histórico cultural. Psicologia em Revista, 17(1), pp. 32-47. Recuperado em 29 de setembro, 2019, de http://pepsic.bvsalud.org/scielo.php?script=sci arttext\&pid=S167711682011000100005

Bock, Ana Mercês Bahia. (2004). A perspectiva histórica da subjetividade: uma exigência para la psicologia atual. Psicologia para América Latina, (1) Recuperado em 31 de outubro de 2019, de http://pepsic.bvsalud.org/scielo.php?script=sci arttext\&pid=S1870350X2004000100002\&lng $=$ pt\&tlng=pt.

Bock, A. M. B. (2001). A Psicologia sócio-histórica: uma perspectiva crítica em Psicologia. In: Bock, A. M. B; Gonçalves, M. G. G.; Furtado, O. (Orgs.). Psicologia sócio-histórica: uma perspectiva crítica em Psicologia. (pp. 15-35). São Paulo: Cortez.

Cambaúva, L. G. \& Tuleski, S. C. (2007). A pseudoconcreticidade do conceito de subjetividade na Psicologia. Revista de Educação, (23), pp. 79-90.

Carmo, Michelly Eustáquia do, \& Guizardi, Francini Lube. (2018). O conceito de vulnerabilidade e seus sentidos para as políticas públicas de saúde e assistência social. Cadernos de Saúde Pública, 34(3), e00101417. Epub March 26, 2018. https://dx.doi.org/10.1590/0102$311 \times 00101417$

Ferrari, B. M., Almeida, C. R., Lopes, C. J. R., Prates, E. C., Mendes, F. C. S., Teixeira, G. N., Gonçalves, J. P .B., Cambraia, K. A. B., Vitor, L. H. O., Caetano, R. L., Rodrigues, S. M. A., Souza, W. A. S. (2010). Mediação e Cidadania (Cap. 1, pp. 11-13). Minas Gerais: ARrAEs.

Gil, A.C (2002) Como elaborar projetos de pesquisa. São Paulo: Atlas S.A.

Gonçalves, M.G.M. (2010). Psicologia, subjetividade e políticas públicas. 1.ed. São Paulo: Cortez.

Gonçalves, M. G. M. (1998). A historicidade da categoría subjetividade. Temas em Psicologia, 6(2), pp. 135-146. Recuperado em 23 de setembro de 2019, de http://pepsic.bvsalud.org/scielo.php?script=sci arttext\&pid=S1413389X1998000200006\&lng=pt\&tIng=pt.

Gustin, M. (2012). Resgate dos direitos humanos em situações adversas de países periféricos. Revista da Faculdade de Direito da UFMG, O(47). Recuperado de https://www.direito.ufmg.br/revista/index.php/revista/article/view/227

Jacques, M. G. C, Strey, M. N., Bernardes, M. G., Guareschi, P. A., Carlos, S. A., \& Fonseca, T. M. G., (2008). Psicologia social contemporânea (11a ed. ). Rio de Janeiro: Vozes.

Leandro, A. G. L., \& da Cruz, G. F. C. (2014). Programa Mediação de Conflitos da Secretaria de Estado de Defesa Social de Minas Gerais: Delineando uma Metodologia em Mediação Individual e Comunitária. 
Lei n. 8742, de 07 de dezembro de 1993 (2013). Lei Orgânica da Assistência Social (Loas). Brasília.

Marx, Karl, \& Engels, Friedrich. (1998). Manifesto do Partido Comunista. Estudos Avançados, 12(34), 7-46. https://dx.doi.org/10.1590/S0103-40141998000300002

Nascimento, L. S., Sarubbi, M. R. M., \& Souza, P. P. (2009). A dimensão subjetiva da desigualdade social: um estudo sobre a dimensão subjetiva da vivência da desigualdade social na cidade de São Paulo. TransFormações em Psicologia, 1(2), pp. 8-37. Recuperado em 29 setembro, 2019, de http://pepsic.bvsalud.org/pdf/transpsi/v2n1/a02.pdf

Sabadini, A. A. Z. P., Sampaio, M. I. C., \& Koller, s. h. (2009). Preparando um artigo científico. São Paulo: ABECiP.

Sawaia, B., Wanderley, M. B., Véras, M., Jodelet, D., Paugam, S., Carreteiro, T. C., Mello, S. L., Guareshi, P. A (2001). As artimanhas da exclusão: análise psicossocial e ética da desigualdade social. Petrópolis: Vozes.

SEBRAE. (2008). Políticas Públicas Conceitos e Práticas. Recuperado em 27 de outubro, 2019, de

http://www.mp.ce.gov.br/nespeciais/promulher/manuais/MANUAL\%20DE\%20POLITICAS $\% 20 \mathrm{P} \% \mathrm{C} 3 \% 9 A B L I C A S . p d f$

Silva, E. S. (2011). As entrelinhas da inclusão/exclusão social na atualidade: uma discussão conceitual. V Jornada internacional de políticas públicas, Paraíba, PB.

Silva, F. G. (2009). Subjetividade, individualidade, personalidade e identidade: concepções a partir da psicologia histórico-cultural. Psicologia da Educação, (28), pp. 169-195. Recuperado em 25 de setembro de 2019, de http://pepsic.bvsalud.org/scielo.php?script=sci arttext\&pid=S1414$69752009000100010 \& \operatorname{lng}=$ pt\&tlng=pt. 